\title{
Correction to: Vulnerability, Harm, and Compromised Ethics Revealed by the Experiences of Queer Birthing Women in Rural Healthcare
}

\author{
Sylvia Burrow (i) • Lisa Goldberg • Jennifer Searle • Megan Aston
}

Published online: 28 November 2018

(C) Journal of Bioethical Inquiry Pty Ltd. 2018

\section{Correction to: Bioethical Inquiry \\ https://doi.org/10.1007/s11673-018-9882-5}

The following Acknowledgments were omitted in the original publication:

Acknowledgments The research has been made possible through the support of partnership funding through the Canadian Institutes of Health Research (IGH), the Nova Scotia Health Research, and the Nursing Research Fund (SON) and Faculty of Health, Dalhousie University, Halifax, NS Canada.

The researchers wish to acknowledge the generosity and courage of the participants without whom the research would not have been made possible.

The online version of the original article can be found at https://doi.org/10.1007/s11673-018-9882-5

S. Burrow $(\bowtie)$

Cape Breton University, 5300 Grand Lake Road, Sydney NS.B1P

6L2, Canada

e-mail: sylvia_burrow@cbu.ca

L. Goldberg · J. Searle · M. Aston

Dalhousie University, 5869 University Avenue, Halifax NS B3H

4R2, Canada

L. Goldberg

e-mail: lisa.goldberg@dal.ca

J. Searle

e-mail: jesearle@dal.ca

M. Aston

e-mail: megan.aston@dal.ca 